\title{
Peptidergic Modulation of Neuronal Circuitry Controlling Feeding in Aplysia
}

\author{
Wayne S. Sossin, Mark D. Kirk, ${ }^{a}$ and Richard H. Scheller \\ Department of Biological Sciences, Stanford University, Stanford, California 94305
}

\begin{abstract}
We examined the effects of 3 neuropeptides and the bioactive amine 5-HT on identified motoneurons (B15 and B16) and interneurons (B4, B5) involved in the control of feeding behavior in Aplysia californica. The application of egg-laying hormone (ELH), small cardioactive peptide $b\left(S C P_{b}\right)$, and 5-HT eliclts distinct patterns of synaptically induced bursting in the neurons, while PheMetArgPheamide (FMRFamide) inhibits firing due to synaptic activity. Repetitive IPSPs recorded in B15 and B16 are induced by 5-HT and SCP $_{b}$ and inhibited by FMRFamide. The substances also may act directly: In solutions that block synaptic transmission $\mathrm{SCP}_{\mathrm{b}}$ excites B15, ELH excites B16, 5-HT excites B15, B16, and $B 4$, and FMRFamide both inhibits B15 and B16 and excites B4. We suggest that the output of a buccal ganglion central pattern generator may be modulated to produce distinct patterns of motoneuron activity by these candidate transmitters. We also noted differences in the intrinsic properties of the 2 motoneurons. B15 contains SCP $_{b}$ immunoreactivity while $B 16$ does not. This finding suggests that $B 15$ may be the source for the $\mathbf{S C P}_{\mathrm{b}}$ immunoreactivity previously found at the ARC muscle and that SCP $_{b}$ may be acting in an autocrine mode. Also, B15 has a significantly lower resting potential than B16 and contains a large transient outward ( $\mathrm{I}_{\mathrm{a}}$-like) current. The candidate transmitters act by exciting or inhibiting elements at every level within the hierarchically organized motor system that controls feeding. This expands the diversity of behavioral repertoires that may be elicited from a particular neural circuit.
\end{abstract}

In recent years, neuropeptides have assumed increasing importance in our attempts to understand neuronal circuitry. The ability of neuropeptides to act nonsynaptically, and over long time periods, adds diversity to nervous system interactions (Krieger, 1983). Furthermore, it is becoming clear that neuropeptides play an important role in controlling and modulating behavior in many organisms (Snyder and Innis, 1979; Krieger, 1983). In an attempt to understand the mechanisms by which neuropeptides act, many investigators have turned their atten-

\footnotetext{
Received Mar. 28, 1986; revised Sept. 5, 1986; accepted Sept. 13, 1986.

We wish to thank Thane Kreiner for his assistance with the immunohistochemical work, and Drs. Corey Goodman, John Kuwada, and Jeff Wine for a critical reading of the manuscript. W.S. is supported in part by a Canadian MRC Studentship. This work was supported by grants to R.H.S. from the NIH and NIMH. R.H.S. is a Klingenstein Fellow in the Neurosciences and the recipient of a Presidential Young Investigator Award.

Correspondence should be addressed to Richard H. Scheller at the above address.

a Present address: Department of Biological Sciences, Boston University, Boston, MA 02215.

Copyright $\mathfrak{C} 1987$ Society for Neuroscience $0270-6474 / 87 / 030671-11 \$ 02.00 / 0$
}

tion to the simpler nervous systems of invertebrate organisms. By virtue of its large identified peptidergic neurons and simple behaviors, the gastropod mollusc Aplysia californica has become a powerful model system for studies of neuropeptide function (e.g., Scheller et al., 1984).

One of the better understood invertebrate behaviors is feeding. In Aplysia, feeding consists of a number of different rhythmic motor patterns, including biting, swallowing, and rejection (Kupfermann, 1974a; Weiss et al., 1986). Each of these behaviors includes, among other motions, rhythmic protractions and retractions of the radula, which is used to grasp food. One of the muscles involved in retracting the radula, the accessory radular closer (ARC) muscle, has been the subject of previous investigations (Cohen et al., 1978; Weiss et al., 1978). Many of the neurons involved in feeding have been identified in the buccal ganglia (Gardner, 1971; Kandel, 1979), including the major ARC muscle motoneurons B15 and B16 (Cohen et al., 1978). B4 and B5 are cholinergic multifunctional neurons that act as sensory neurons, premotor interneurons, and motor neurons (Gardner, 1977; Rosen et al., 1982; Jahan-Parwar et al., 1983). Acting as premotor interneurons, they inhibit the retractor motoneurons B15 and B16, excite the protractor motoneuron B13, and have a dual effect on another protractor motoneuron, B7 (Gardner, 1977).

Immunohistochemical, biochemical, and molecular genetic techniques have been used to localize small cardioactive peptide b $\left(\mathrm{SCP}_{\mathrm{b}}\right)$ (Lloyd et al., 1985; Mahon et al., 1985), PheMetArgPhe- $\mathrm{NH}_{2}$ (FMRFamide) (Schaefer et al., 1985), and the egglaying hormone (ELH) (McAllister et al., 1983; Shyamala et al., 1986 ) to the $A$. californica buccal ganglia. Furthermore, these neuropeptides have been shown to have physiological effects on certain aspects of feeding in gastropods. $\mathrm{SCP}_{\mathrm{b}}$ increases the intensity of the central motor program for feeding in Tritonia (Lloyd and Willows, 1980) and Helisoma (Murphy et al., 1985), while FMRFamide inhibits the feeding motor program in Helisoma (Murphy et al., 1985). As part of the egg-laying fixed action pattern, ELH inhibits feeding in Aplysia (Stuart and Strumwasser, 1980; Cobbs and Pinsker, 1982a, b). These data suggest that these substances may function as transmitters in the Aplysia buccal ganglia.

Additional inputs that modulate feeding have been identified in Aplysia. 5-HT immunoreactivity is found in the buccal ganglia (Goldstein et al., 1984), and the metacerebral cell (MCC), a serotonergic cerebral neuron with processes in the buccal ganglia and buccal muscles, is involved in food-induced arousal (Weiss et al., 1978; Rosen et al., 1983). The MCC excites B15 and B16, and acts directly on the ARC muscle to enhance tension development in response to motoneuron stimulation (Weiss 


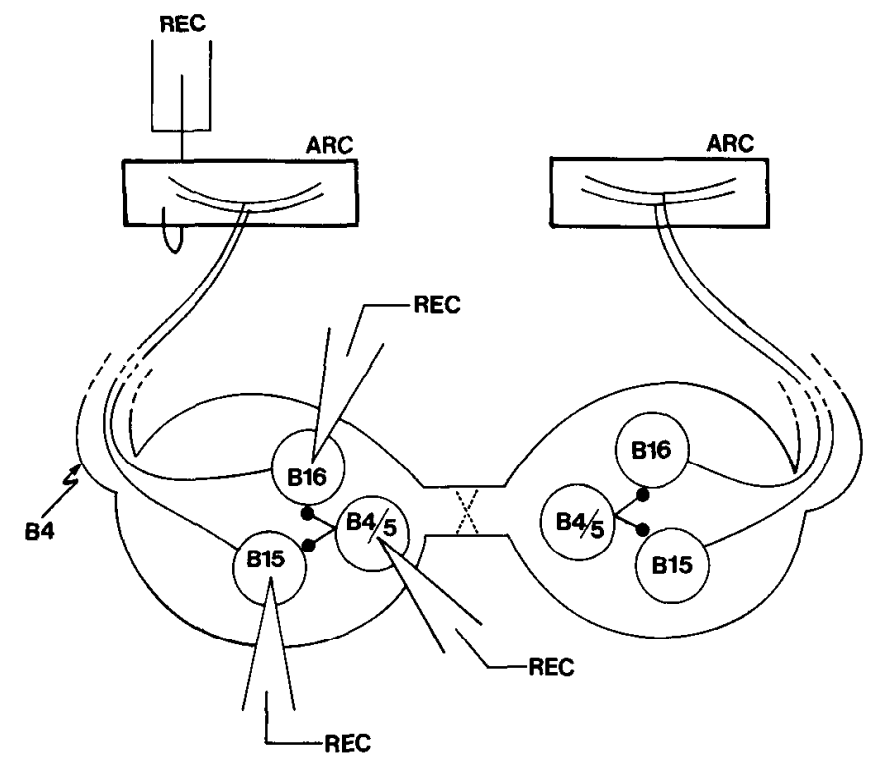

Figure 1. Schematic of experimental preparation. The drawing is not to scale but is illustrative of the general experimental setup. The dotted $X$ through the commissure indicates that the commissure was occasionally severed without altering the results. The identified cells and the ARC muscle from which we recorded are indicated, as is the nerve (B4) connecting each ganglion to the ARC muscle. B4/5 indicates that we recorded from either B4 or B5 in the experiments.

et al., 1978). Direct applications of $\mathrm{SCP}_{\mathrm{b}}$ and 5-HT have also been shown to potentiate the effects of $B 15$ and B 16 on the ARC muscle (Lloyd et al., 1984). In addition, ELH and 5-HT depolarize B16 directly (Ram, 1983; Kirk et al., 1985; Ram et al., 1986) by activating a slow inward current (Kirk and Scheller, 1986).

Central pattern generators (CPGs) are thought to be important in controlling many rhythmic behaviors (e.g., feeding) in molluscs and other organisms, including vertebrates (Kater, 1974; Delcomyn, 1980; Selverston, 1980; Grillner, 1985). In the invertebrate CNS, CPGs consist of a set of interconnected interneurons that produces a rhythmically patterned output and distributes this patterned output to motoneurons (Stent et al., 1978; Benjamin and Rose, 1980; Getting, 1981). Alternatively, in simpler invertebrate systems, the CPG may consist mostly of interconnected motoneurons (Selverston et al., 1976), some of which exhibit endogenous bursting or plateau potential properties (Russell and Hartline, 1982).

We describe here a number of effects of 4 buccal candidate transmitters (SCP, FMRFamide, ELH, and 5-HT) on the identified neurons B4/B5, B15, and B16 and the CPG(s) that controls them. By modulating activities of effector elements at different levels within the motor system - from the CPG(s) to the muscles - the candidate transmitters can profoundly alter the resultant motor outputs of the buccal ganglia.

\section{Materials and Methods}

Aplysia californica (50-250 gm; Sea Life Supply, Seaside, CA) were used for all experiments. The results presented here are taken from a total of 25 preparations. All experiments were performed at room temperature $\left(22-25^{\circ} \mathrm{C}\right)$.

The buccal ganglia and the ARC muscle were removed with the peripheral nerve B4 [Fig. 1; nomenclature according to Kandel (1979)] to the ARC muscle attached. The preparation was placed in a 2 chambered dish lined with Sylgard. The muscles and ganglia were put in separate baths isolated by an intervening partition formed with petroleum jelly. Trypsin (Sigma Type IX, $10 \mathrm{mg} / \mathrm{ml}$ ) was added to the buccal ganglia for a period of 5-15 min. The ganglia were generally then desheathed in preparation for the insertion of the recording electrodes. Variations in this procedure included omitting the trypsin or the desheathing steps to ensure the rhythms produced were not affected by these treatments. The only differences noted were longer latencies to peptide actions in the nondesheathed preparations. In a number of preparations a single buccal ganglion was isolated by cutting the commissure between the 2 buccal ganglia. No differences in the observed rhythms were noted following this procedure.

The 2 motoneurons were identified on the basis of position and electrical properties, and by correlating their action potentials with ARC muscle extrajunctional potentials (EJPs) (Cohen et al., 1978). B4/B5 could usually be identified on the basis of position and size, although the identifications were further verified by their inhibition of B15 and B16. Although we have no other reliable criteria for differentiating B4 from B5, we have usually considered the more medial of the 2 to be B4 (Gardner, 1977). We observed no differences in the responses of the 2 cells, and in the rest of this paper we will refer to B4 with the understanding that the conclusions apply to B5 as well.

The recording situation is illustrated in Figure 1. Intracellular recordings were routinely made from $B 4, B 15$, and $B 16$ with $3 \mathrm{M}$ potassium acetate microelectrodes (8-15 M $)$ ) using conventional electrophysiological equipment and plotted with a brush pen recorder (Gould). The recordings were also tape-recorded (FM recording, Vetter recorder) and later replayed using faster chart speeds to examine the synaptic activity. The 2 electrode voltage-clamp apparatus and techniques are described in Kirk and Scheller (1986).

Normal artificial seawater (ASW) had the following composition: 490 $\mathrm{mm} \mathrm{NaCl}, 11 \mathrm{~mm} \mathrm{KCl}, 19 \mathrm{~mm} \mathrm{MgCl}, 30 \mathrm{~mm} \mathrm{MgSO}_{4}, 11 \mathrm{~mm} \mathrm{CaCl}_{2}$, and $10 \mathrm{~mm}$ Tris (pH 7.6). The solution used to block chemical synaptic activity contained $10 \mathrm{~mm}$ cobalt, which substituted for calcium, and occasionally a solution was used with normal calcium and $10 \mathrm{~mm}$ cobalt added. SCP $_{b}$ and FMRFamide were purchased from Peninsula Labs. Stock solutions of $100 \mu \mathrm{M}$ were made and stored at -20 or $-70^{\circ} \mathrm{C}$ before use. 5-HT (Sigma) was used from stock solutions of 1 or $10 \mathrm{~mm}$ made the day of the experiment or stored at $-20^{\circ} \mathrm{C}$. ELH was either purified from bag cells (Chiu et al., 1979; see Kirk and Scheller, 1986) or made synthetically to $50 \%$ purity (Peninsula Labs) and then further purified using high-pressure liquid chromatography. ELH stock solutions $(20 \mu \mathrm{M})$ were stored at -20 or $-70^{\circ} \mathrm{C}$ before use. All solutions were warmed to room temperature in a water bath before application.

The candidate transmitters were bath-applied from the concentrated solutions, which were diluted by the bath volume to give the final concentrations as stated in the text. With bath application latencies were somewhat variable because of diffusion and depended on the location of the application. Substances were washed out by using a bath perfusion system. Washes consisted of a minimum exchange of 10 bath volumes (bath volume was $1 \mathrm{ml}$ ).

Dye injections and immunohistochemistry. For these experiments, the initial preparation was the same as for the electrophysiology experiments described above. (The ganglia were desheathed and the cells identified by the same criteria.) Lucifer yellow ( $2 \% \mathrm{wt} / \mathrm{vol}$ ) was then iontophoresed into the identified cells using a current of $10 \mathrm{nA}$ for $15-30 \mathrm{~min}$. The electrodes used for the fills had resistances of 10-30 MN. Only 1 cell in each ganglion was injected so as to avoid possible confusion. The cells were then fixed, sectioned, and processed for immunohistochemistry. A previously characterized anti-SCP ${ }_{b}$ rabbit antiserum was used along with standard controls as previously described (Lloyd ct al., 1985; Mahon et al., 1985). Rhodamine-labeled secondary antibody (Cappel) was used so that the injected cell and the immunohistochemical staining could be differentiated by using different filters on a Zeiss immunofluorescence scope. Each experiment was repeated at least twice.

\section{Results}

\section{Effects of $\mathrm{SCP}_{\mathrm{b}}, 5-\mathrm{HT}$, ELH, and FMRFamide}

For each substance, we first describe the unique pattern of activity elicited. Furthermore, we divide the bursts into discrete phases, both to facilitate discussion and to serve as a basis for identifying these bursts in future experiments. Finally, we describe effects that persist in solutions that block synaptic transmission. Operationally, we call these direct effects, although it 

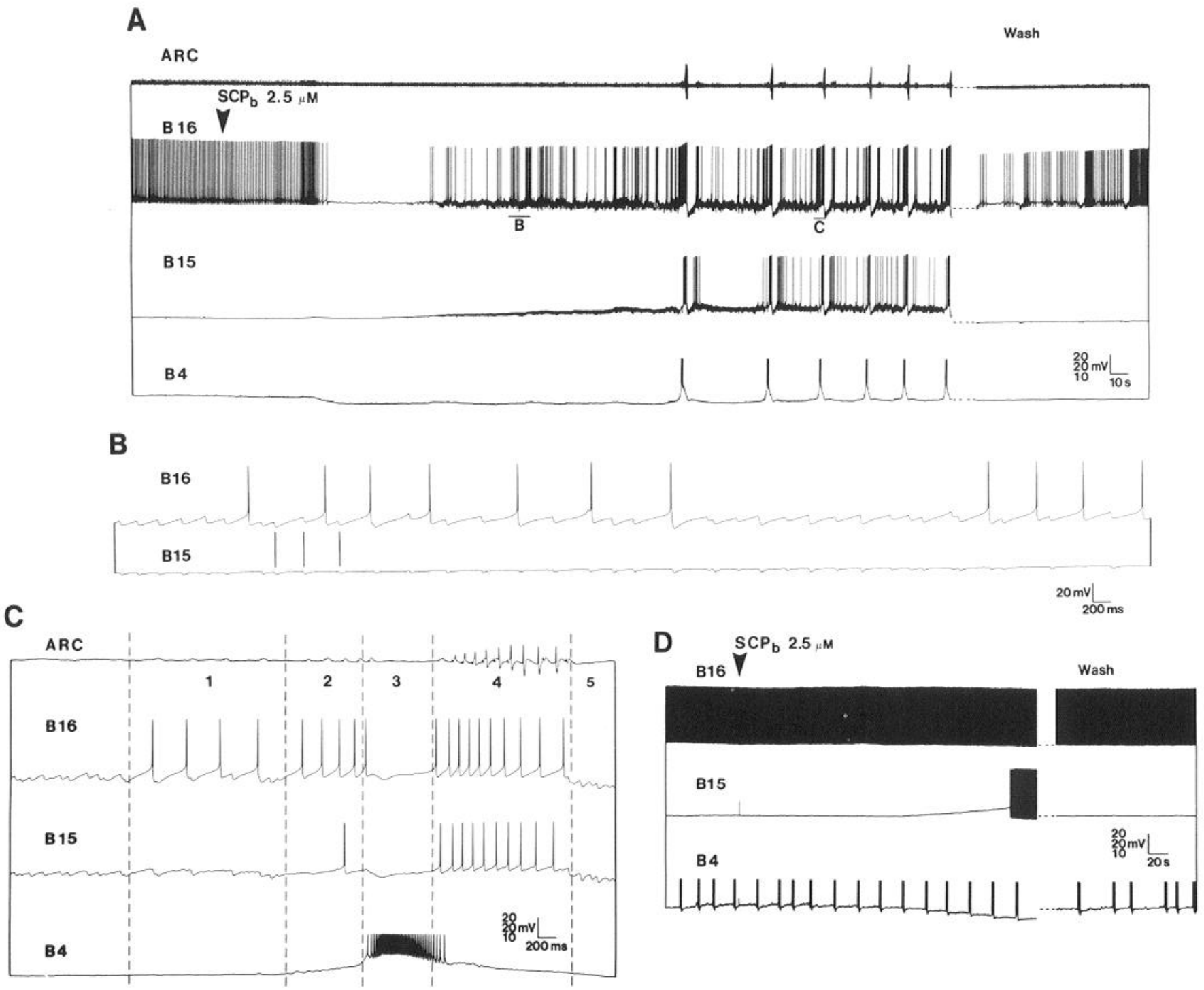

Figure 2. Effects of $\mathrm{SCP}_{\mathrm{b}}$ on buccal neurons. Calibrations for the intracellular recordings are as indicated on the tracings. The extracellular ARC muscle recording is uncalibrated. Solid vertical lines connect simultaneous recordings. $A, \mathrm{SCP}_{\mathrm{b}}$ induces a unique pattern of rhythmic bursting activity in the identified neurons. The action potentials in these recordings and those of the remaining figures were occasionally clipped by the chart recorder (e.g., B4). The arrowhead marks the addition of $2.5 \mu \mathrm{M} \mathrm{SCP}$. The prolonged hyperpolarization seen in all 3 neurons soon after peptide addition is probably of synaptic origin but was not usually seen after addition of $\mathrm{SCP}_{\mathrm{b}}$. Tonic IPSPs common to B15 and B16 began about 1 min after addition of the peptide, and synaptic bursting was first seen 3 min after peptide addition. The bursts increase in frequency until the interburst interval reaches $15 \mathrm{sec}$. The dotted line indicates a $12 \mathrm{~min}$ wash with normal ASW. After the wash, both the IPSPs and the synaptic bursts ceased, and the depolarization of $\mathrm{B} 15$ caused by $\mathrm{SCP}_{\mathrm{b}}$ washed away. The underlined regions are expanded in $B$ and $C$. B, IPSPs are 1 for 1 in $\mathrm{B} 15$ and B16. Expansion of indicated region of $A$. The lines have been drawn to demonstrate the coordination of IPSPs in the 2 cells. $C$, Expanded view of an $\mathrm{SCP}_{b}$-induced burst. Expansion of indicated region of $A$. The dashed vertical lines separate phases 1-5 (see text for discussion). $D$, Effects of 2.5 $\mu \mathrm{M} \mathrm{SCP}$ in no calcium cobalt solutions. Different preparation than in $A-C$. Recordings were from experiments performed in solutions in which calcium was replaced by $10 \mathrm{~mm}$ cobalt. Addition of peptide is indicated by the arrowhead. B15 is depolarized by the peptide and begins to fire tonically approximately 2 min after addition of the peptide. Higher-speed B16 recordings showed no change in frequency of firing after addition of $\mathrm{SCP}_{\mathrm{b}}$. The effect on $\mathrm{B} 4$ is not due to $\mathrm{SCP}_{\mathrm{b}}$ (see text). Dotted line indicates a wash of 10 bath volumes over a period of $5 \mathrm{~min}$.

cannot be ruled out that these are effects on unknown electrically coupled neurons.

\section{Small cardioactive peptide $b$}

Bath application of $2.5 \mu \mathrm{M} \mathrm{SCP}$ resulted in a sequence of synaptic inputs that eventually gave rise to rhythmic bursting activity in the identified neurons. A typical response to $\mathrm{SCP}_{\mathrm{b}}$ is shown in Figure $2 A$. Initially, repetitively occurring, discrete IPSPs were induced in B15 and B16 with a latency of $105 \pm$ 80 (SD) $\sec (n=17)$. These IPSPs were 1 for 1 in both moto- neurons (Fig. $2 B$ ) and therefore probably arose from a common input(s). The IPSPs were also seen in a number of other neurons in the buccal ganglia (e.g., B9, B11), and they may be identical to those described by Cohen et al. (1978). At slightly longer latencies, rhythmic bursting synaptic activity was induced with a latency of $3.9 \pm 1.7$ (SD) $\min (n=13)$, indicating the induction of activity in a CPG. A single burst is seen on an expanded time scale in Figure $2 C$. It can be divided into 5 phases based on the nature of the inputs recorded in B4, B15, and B16. During phase 1 , the frequency of IPSPs in B15 and B16 decreased. B16 usually 


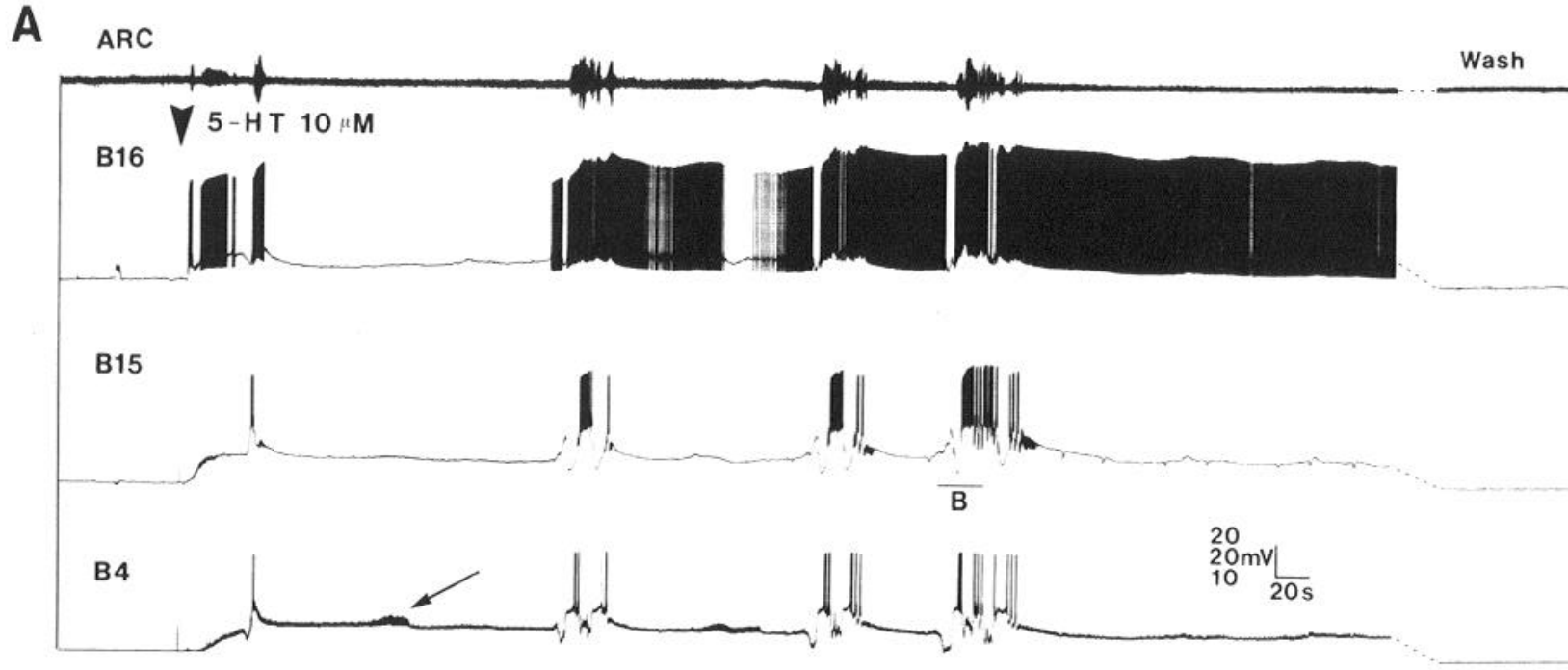

B

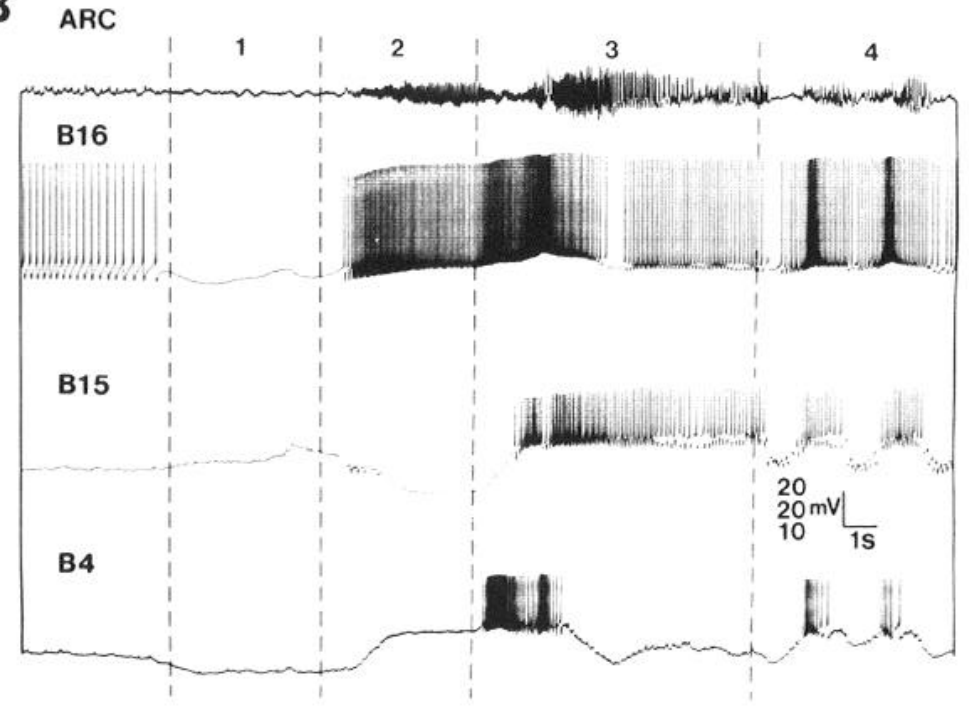

C

Wash

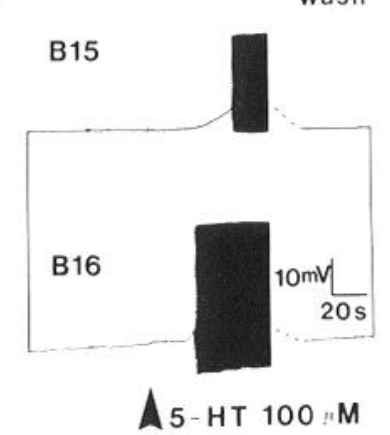

B4

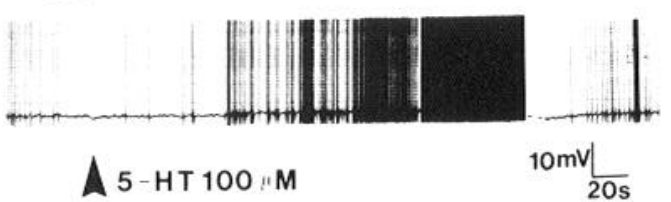

Figure 3. Effects of 5-HT on buccal neurons. A, 5-HT elicits bursts of synaptic input to the identified neurons. The arrowhead marks the addition of $10 \mu \mathrm{m} 5-\mathrm{HT}$. Within $20 \mathrm{sec}$ after addition of 5-HT, all 3 neurons began to depolarize and in under a minute the first burst of synaptic activity in all 3 cells can be seen. The decrease in synaptic activity after prolonged addition of 5-HT seen in this figure may be due to desensitization or the delayed induction of inhibitors that shut off the synaptic activity to the cells under observation. The dotted line indicates a wash of 7 min with normal ASW. Underlined region is expanded in B. The arrow indicates a burst of EPSPs in B4. B, 5-HT burst consists of a number of components. Expansion of $A$. Dotted lines separate each phase. The phases can be identified by the following features: phase 1, B15 is strongly depolarized, while B4 and B15 are both inhibited; phase 2, B4 and B16 are both depolarized, while B15 is strongly inhibited; phase 3, initially all 3 neurons are excited, but this excitation is followed by an inhibitory input to B4 and B16 while the excitation to B15 is sustained; phase 4 , all 3 neurons receive short excitatory inputs separated by inhibitory inputs. This phase is often seen near the end of a long bout of 5-HT-induced synaptic activity and the bursts damp at the end. C, 5-HT excites B4, B15, and B16 in solutions that block synaptic activity. Results are from 2 separate experiments. The arrowhead indicates the addition of $100 \mu \mathrm{m} \mathrm{5-HT}$. The 2 upper traces are from an experiment in a solution in which 10 mM cobalt was added to normal ASW to block synaptic activity. Unlike the solutions in which cobalt replaced calcium, tonic firing in B16 was not induced, and therefore the effect of 5-HT on B16 is highlighted. The B4 recording is from an experiment in which calcium was replaced by $10 \mathrm{~mm}$ cobalt. Dotted line indicates a wash of 10 bath volumes over a period of $5 \mathrm{~min}$.

fired after being released from inhibition. In phase 2, excitatory inputs were received in all 3 cells, and the IPSPs in B15 and $\mathrm{B} 16$ ceased, resulting in B16 firing at increased frequency while B15 occasionally reached threshold. Phase 3 began when B4 reached threshold and began to fire at very high frequencies (approximately $50 \mathrm{~Hz}$ in Fig. 2C), which inhibited B15 and B16. In 4 out of 12 cases in which the inhibition from $\mathrm{B} 4$ could be assessed, B15 and B16 were totally inhibited (Fig. 2C, phase 3). In 6 out of 12 cases, the firing of B15 and B16 was significantly inhibited (decrease in B16 firing frequency, no B15 spikes), and in 2 of the cases, B4 did not fire during the burst or fired at such a low frequency as to have no observable effect on the firing frequency in B15 and B16. In phase 4, B4 was silent and both $\mathrm{B} 15$ and B16 fired at high frequency. Although muscle tension was not monitored, the main muscular movement would probably occur during this period of intense B15 activity due to the dramatic neuromuscular facilitation (Fig. 2, $A, C$, the ARC recording; Cohen et al., 1978). In phase 5, the disappearance of the excitatory inputs was coupled with strong inhibitions in B15 and B16. The minimum interburst interval seen was $15 \mathrm{sec}$. 
The 5 phases described above were present in virtually all experiments; however, an additional preburst phase of activity was seen in approximately $50 \%$ of the preparations. This phase consisted of a hyperpolarization in B15 coupled to small excitations in B4 and B16. While B4 rarely reached threshold during this phase, B16 often fired during this period. Occasionally $(n=$ 3), each $\mathrm{SCP}_{\mathrm{b}}$ burst was preceded by 2-3 preburst phases of this variety. Although a complete dose-response curve was not obtained, irregular synaptic bursts were induced at concentrations as low as $250 \mathrm{~nm} \mathrm{SCP}_{\mathrm{b}}$.

\section{Direct effects of $S C P_{b}$ on identified neurons}

In normal ASW $(n=15)$, B15 was depolarized $6.9 \pm 4.2$ (SD) $\mathrm{mV}$ (mean peak depolarization) by $2.5 \mu \mathrm{M} \mathrm{SCP}$. This excitation appeared despite the concurrent induction of tonic inhibitions. To show that this effect may occur directly on B15, chemical synaptic transmission was blocked by perfusing the bath with a solution in which $10 \mathrm{~mm}$ cobalt was substituted for calcium. Synaptic activity was not observed in this solution, and the monosynaptic connections between B4 and B15 or between B4 and B16 could not be seen even if B4 was fired at high frequencies. Addition of $2.5 \mu \mathrm{M} \mathrm{SCP}$ now resulted in a depolarization of B15; this led to tonic firing with a latency of $2.7 \pm$ 1.5 (SD) $\min (n=6$; see Fig. $2 D)$, suggesting a direct excitatory action of the peptide. Besides blocking synaptic activity, the cobalt solution depolarized the neurons; this resulted in spontaneous activity in $\mathrm{B} 16$, bursting in $\mathrm{B} 4$, and subthreshold depolarization in B15 (see Fig. $2 D$, before application of the peptide). These actions always stablilized before the addition of transmitter. The hyperpolarization of $\mathrm{B} 4$ after addition of $\mathrm{SCP}_{\mathrm{b}}$ seen in Figure $2 D$ was not due to actions of the peptide, but rather to the carrier solution (normal ASW), since applications of equal volumes of normal ASW to the bath produced the same effect. Addition of equal volumes of normal ASW had no effect on $\mathrm{B} 15$ or $\mathrm{B} 16$ in this preparation.

\section{Biogenic amine 5-HT}

5-HT induced a complex bursting pattern in the ARC motor neurons and B4 [at 10-100 $\mu \mathrm{M} 5-\mathrm{HT}$, latency was $2.9 \pm 3$ (SD) $\min ; n=11]$. An experiment in which $10 \mu \mathrm{M} 5$-HT induced bursting is shown in Figure $3 A$. The 5-HT bursting is not as regular or consistent as that induced by $\mathrm{SCP}_{\mathrm{b}}$ in that the ordering of the phases varied among the preparations; additionally, the interburst intervals are quite irregular within preparations. The 4 phases of a 5-HT-induced burst were quite consistent, as illustrated in Figure $3 B$. Excitatory and inhibitory synaptic activities in B4 and B16 were in phase, whereas PSPs in B 15 were often of the opposite polarity. Thus, activity in B 15 and another large identified cell, $\mathrm{B} 9(n=3)$, appeared antiphasic with respect to activities in B4 and B16.

There were several similarities in the burst phases elicited by 5-HT and $\mathrm{SCP}_{\mathrm{b}}$. Phase 2 of the 5-HT burst was similar to the preburst phase during the response to $\mathrm{SCP}_{\mathrm{b}}$, and both in phase 4 of the 5-HT- and in phase 3 of the $\mathrm{SCP}_{\mathrm{b}}$-induced bursts, all 3 neurons received simultaneous excitatory input. Despite these similarities, overall features of the bursts were quite distinct. Phases 1 and 3 of the 5-HT response have no counterparts in the $\mathrm{SCP}_{b}$ response, while phases 2 and 4 of the $\mathrm{SCP}_{b}$ response have none in the 5-HT response. The duration of the 5-HTinduced burst was much longer (approximately $20 \mathrm{sec}$, although this was highly variable) than the duration of the $\mathrm{SCP}_{\mathrm{b}}$-induced burst (approximately $3 \mathrm{sec}$ ). Therefore, we can state with some assurance that the bursts observed during the additions of the 2 candidate neurotransmitters were distinct.

Apart from stimulating a CPG, 5-HT has additional effects on the system. Repetitively occurring IPSPs similar to those described for $\mathrm{SCP}_{\mathrm{b}}$ were induced at a latency of $1.7 \pm 1.6$ (SD) min at $100 \mu \mathrm{M} 5$-HT $(n=12)$. EPSPs were often induced in B4 $(n=6)$ by $5-\mathrm{HT}$, and bursts of EPSPs in B4 were also observed (see arrow in Fig. 3A) but not in coordination with the complex bursts discussed above.

\section{Direct effects of 5-HT on identified neurons}

In normal ASW, $100 \mu \mathrm{M}$ 5-HT depolarized B4, B15, and B16 with mean peak depolarizations of $5.9 \pm 3.6(\mathrm{SD}) \mathrm{mV}(n=7)$ and $11.8 \pm 7.2(\mathrm{SD}) \mathrm{mV}(n=8)$ for B4 and B15, respectively, and an excitation to tonic firing in B16 $(n-6)$. The excitation seen in B15 and B16 occurred despite the concurrent induction of IPSPs by 5-HT. These effects appeared to be direct, since they persisted in solutions where cobalt was substituted for calcium in which synaptic transmission would be blocked $(n=6$; see Fig. 3C). The direct effects of 5-HT were also distinct from those of $\mathrm{SCP}_{b}$, as 5-HT depolarized all 3 identified neurons while $\mathrm{SCP}_{\mathrm{b}}$ only affected B15.

\section{Egg-laying hormone}

ELH elicited bursts of synaptic input to B4, B15, and B16 or increased the frequency of their spontaneously occurring bursts of synaptic activity ( $n=7$; also see Ram, 1982, fig. 1 ). This is illustrated in Figure $4 A$; a single burst is shown on an expanded time scale in Figure $4 C$. Note that because of its intrinsic membrane properties (see below), B15 did not fire during this period, even though it received excitatory synaptic input. In contrast to $\mathrm{SCP}_{\mathrm{b}}$-induced activity, $\mathrm{B} 4$ continued firing throughout the duration of the burst. The IPSPs seen in B15 during the burst were probably a direct result of firing in B4. [The IPSPs were phase-locked to the B4 spike, with a short, fixed latency of approximately $5 \mathrm{msec}$ (data not shown).] The continued occurrence of synaptic bursts (Fig. $4 B$ ), even after 30 min of washing, was also a common feature of the response to ELH. As was also shown previously, ELH directly depolarized B16 (Stuart and Strumwasser, 1980; Ram, 1983; Kirk and Scheller, 1986) but it had no effect on B4 or B15 (data not shown; Ram, 1983). The induction of synaptically elicited bursting appears to require a concentration of ELH considerably higher (approximately 500 $\mathrm{nM})$ than required for an observable direct effect on B16 $(<50$ $\mathrm{nM}$ ), but we have noted a large degree of variability in the response. This variability may be the result of differences in the preparations of ELH and/or differences in the responsiveness of the neurons to ELH.

\section{PheMetArgPhe- $\mathrm{NH}_{2}$}

FMRFamide had generally inhibitory effects on the CPG, and thus its actions were difficult to discern in experiments in which there was no spontaneous activity. During spontaneous CPG activity the addition of $2.5 \mu \mathrm{M}$ FMRFamide always inhibited synaptic output from the CPG [latency of $1.5 \pm 1.2$ (SD) min, $n=4$ ]. An example of this inhibition is shown in Figure $5 A$. Bursting was totally inhibited, as were the repetitively occurring IPSPs to B15 and B16. Both activities returned after the FMRFamide was washed out. In 3 out of 20 cases, an unusual form of bursting activity followed the addition of $2.5 \mu \mathrm{M}$ FMRFamide. This bursting exhibited a unique pattern consisting of a combination of IPSPs and EPSPs recorded in B4 and 
A

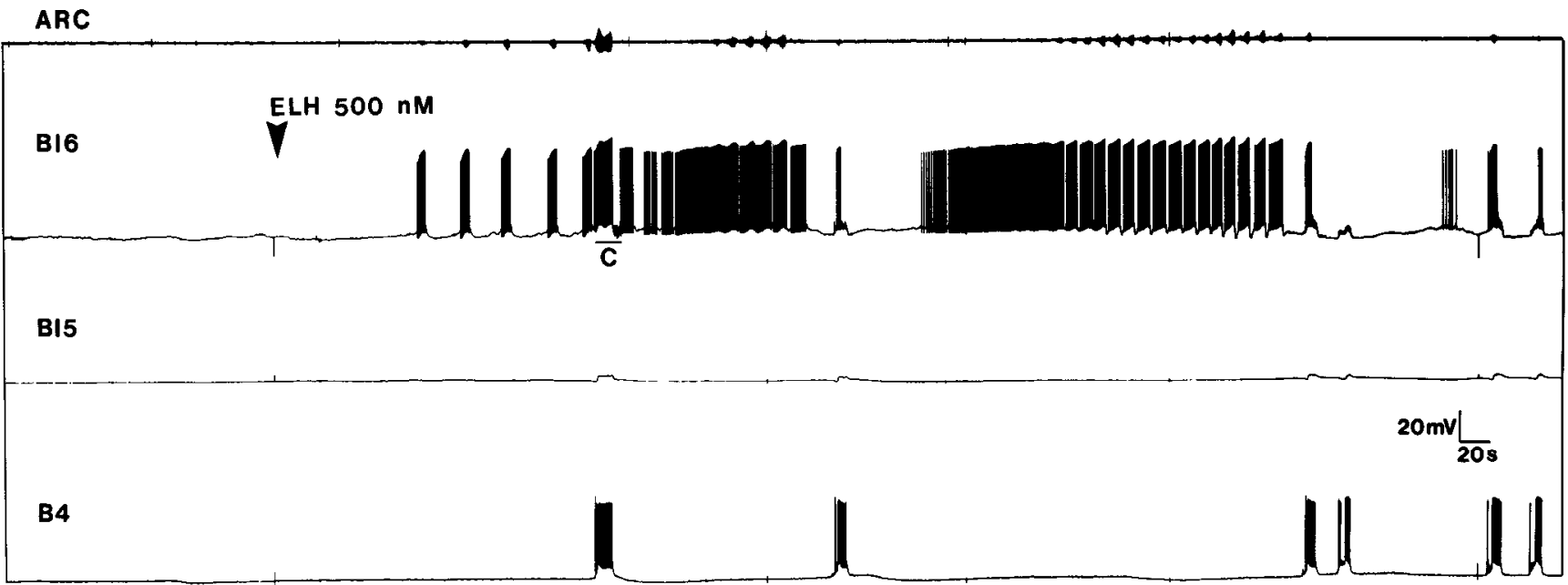

B

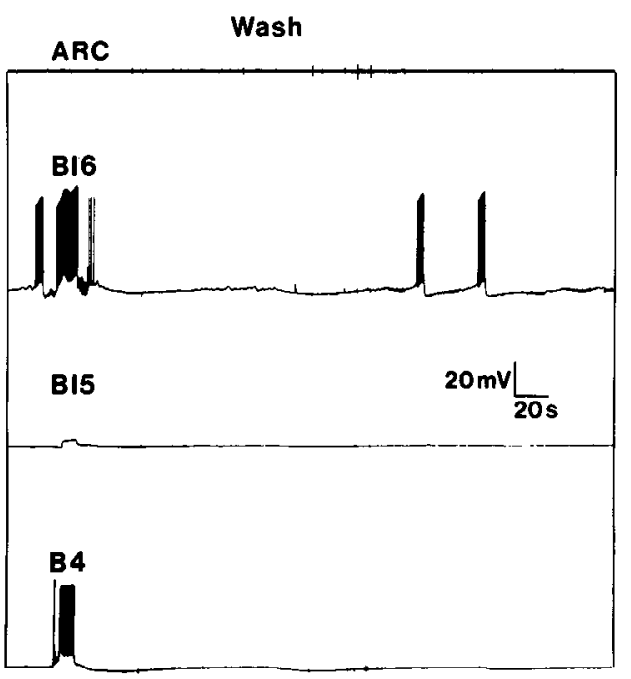

C

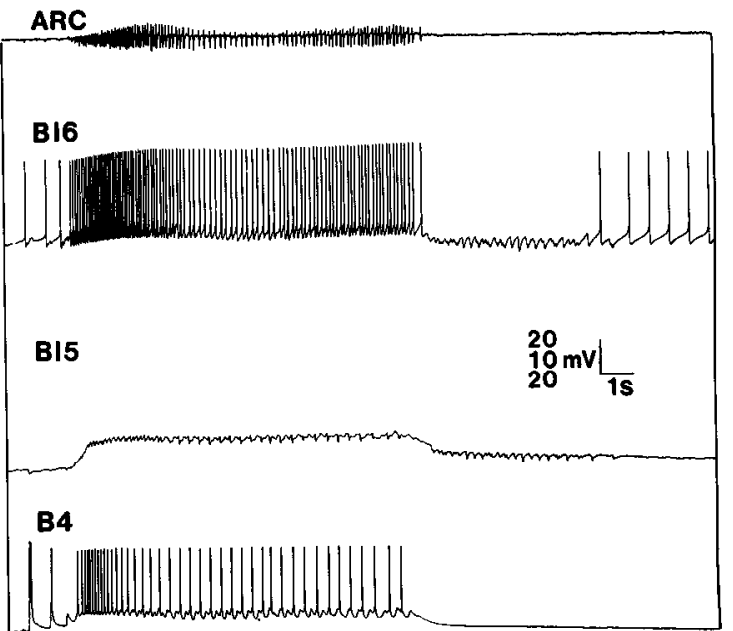

Figure 4. Effects of ELH on buccal neurons. A, ELH elicits synaptic bursting in the identified neurons. The arrowhead marks the addition of 500 nM ELH. The first set of bursts in B16 appear to be endogenous, as no accompanying activity is seen in the other neurons, and B16, when depolarized, does exhibit endogenous bursting (Kirk and Scheller, 1986). Synaptic bursts in all 3 neurons are then induced and occur at irregular intervals. The underlined region is expanded in $C . B$. The ELH effect slowly washes out. This record was taken 30 min after continuous wash following the ELH response shown in $A$. Bursts are still evident, although B16 has almost returned to its normal resting potential. $C$, Expanded view of an ELHinduced burst underlined in $A$ (see text for discussion). Note that the IPSPs in B15 during the burst emanate from B4.

B16 with little or no synaptic input to B15 (data not shown). This form of activity did not appear to occur fortuitously, as it was never observed spontaneously.

\section{Direct effects of FMRFamide on identified neurons}

FMRFamide had effects on all 3 identified neurons. In normal ASW, $2.5 \mu \mathrm{M}$ FMRFamide hyperpolarized B15 and B 16 [mean peak hyperpolarizations of $-2.6 \pm 2.1$ (SD) $\mathrm{mV}, n=14$, and $-2.3 \pm 2.3$ (SD) $\mathrm{mV}, n=9$, respectively]. In some cases only a decrease in the frequency of spontaneous firing in B16 was observed. FMRFamide also depolarized B4 (mean peak depolarization of $2.8 \pm 2.7$ (SD) $\mathrm{mV}, n=10$ ). Occasionally, FMRFamide also caused an initial transient inhibition in B4, as seen in Figure $5 B$. All these effects persisted in solutions in which synaptic activity was blocked ( $n=6$; see Fig. $5 B$ ), suggesting that FMRFamide acts directly on the neurons. The actions of FMRFamide were less dramatic than those of the other peptides and often diminished even before the peptide was washed out. Both the direct and indirect effects are consistent with a coordinated inhibitory action of the peptide at different levels of the motor control hierarchy.

\section{Intrinsic properties of the identified neurons}

$B 15$ but not $B 16$ contains $S C P_{b}$ immunoreactivity

$\mathrm{B} 15, \mathrm{~B} 16$, and B4 were identified in desheathed buccal ganglia by intracellular recordings and by their actions at the ARC muscle. The identified cells were then injected with Lucifer yellow. The ganglia were fixed, sectioned, and reacted with an anti$\mathrm{SCP}_{\mathrm{b}}$ antibody (Lloyd et al., 1985; Mahon et al., 1985) and then with a rhodamine-conjugated secondary antibody. The cells were examined using fluorescence microscopy and photographed with different filters to identify the injected and $\mathrm{SCP}_{\mathrm{b}}$-immunoreactive cells. B1 5 contains $\mathrm{SCP}_{\mathrm{b}}$ immunoreactivity while $\mathrm{B} 16$ does not (Fig. 6). Additional experiments, similar to that exhibited 

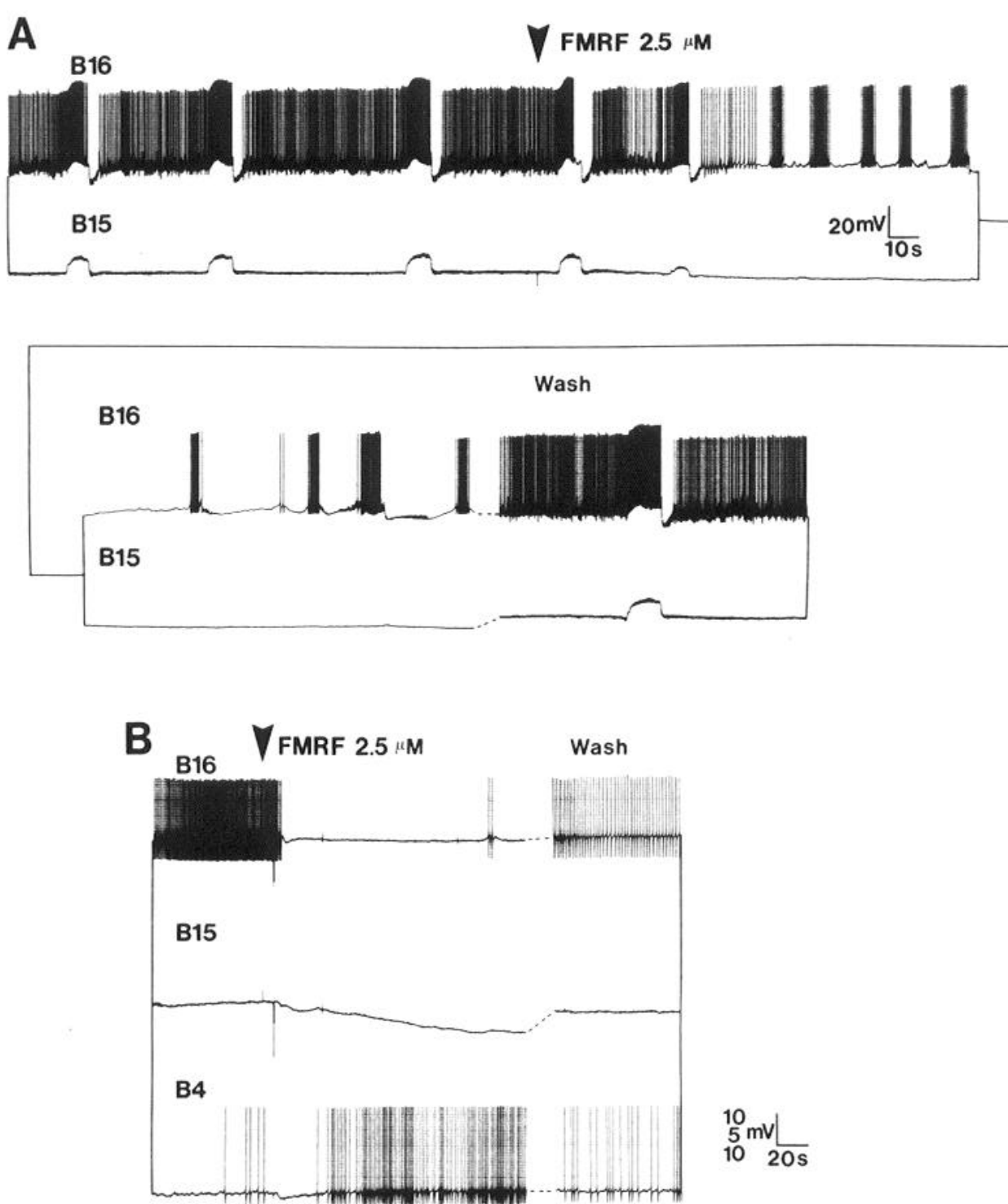

Figure 5. Effects of $2.5 \mu \mathrm{M}$ FMRFamide on buccal neurons. $A$, FMRFamide inhibits ongoing CPG activity. The solid horizontal line connecting the 2 sets of tracings indicates that the recordings are continuous. The arrowhead marks the addition of $2.5 \mu \mathrm{M}$ FMRFamide. The continued activity in B16 after addition of the peptide may reflect excitatory synaptic input elicited by FMRFamide. The dotted line indicates a 5 min wash. $B$, FMRFamide inhibits $\mathrm{B} 15$ and B16 and excites B4 in calciumfree cobalt solutions. This experiment was on a different preparation from that in $A$. Calcium was replaced by cobalt to block synaptic activity. The arrowhead indicates addition of $2.5 \mu \mathrm{M}$ FMRFamide. The dotted line indicates a wash of 10 bath volumes over $5 \mathrm{~min}$. in Figure 6, demonstrated that $\mathrm{B} 4$ does not contain $\mathrm{SCP}_{\mathrm{b}}$ immunoreactivity and that neither B15 nor B16 reacts with an FMRFamide antibody (data not shown). Previous work (McAllister et al., 1983) has not shown ELH immunoreactivity in the region of the buccal ganglia containing B4, B15, and B16. These data are consistent with the observation that B1 5 contains dense-core vesicles characteristic of peptidergic neurons, while B16 and B4 do not (T. Kreiner and R. Scheller, personal communication).

\section{Differential membrane properties of motoneurons B15 and B16}

The motoneurons known to innervate the ARC muscle, B15 and B16, have very different intrinsic physiological characteristics, which influence their responses to both synaptic input and neurotransmitters. The resting membrane potential of $\mathrm{B} 15$ $(-67.8 \pm 5.7 \mathrm{mV}, n=10)$ is significantly more negative than that of B16 ( $-51.9 \pm 5.7 \mathrm{mV}, n=8 ; p<0.01$, Student's $t$ test), although the firing threshold levels of the 2 neurons are similar (approximately -40 to $-45 \mathrm{mV}$ ).

In current clamp, B15 does not begin firing for a long period (approximately $500 \mathrm{msec}$ ) during a sustained depolarization from its normal resting membrane potential of $-70 \mathrm{mV}$ (Fig. 7A1). Upon reaching threshold for repetitive firing, the interspike interval is much shorter (approximately $70 \mathrm{msec}$ ) than the initial latency (Fig. 7Al). The initial latency to repetitive firing was not due to the time constant of B15's membrane, because the membrane potential reaches steady-state levels within tens of milliseconds in response to a hyperpolarizing current pulse of equal magnitude (Fig. 7A1, second current pulse). When a suprathreshold depolarizing current pulse is given from a holding level of $-40 \mathrm{mV}$ (Fig. $7 \mathrm{Bl}$ ), the initial long delay is not seen. Instead, the latency to the first spike was very similar to both the interspike interval and the time to steady-state voltage after a hyperpolarizing current pulse of equal magnitude (Fig. 7B1, second current pulse). To investigate the current(s) that gave rise to the delayed response, B15 was voltage-clamped and stepped to depolarized voltage levels $(-35,-30$, and $-25 \mathrm{mV})$ from a holding potential of either -70 or $-40 \mathrm{mV}$ (see inset in Fig. 7A2). When stepped from a holding potential of -70 $\mathrm{mV}$, a large transient outward current was observed (Fig. 7B1), whereas this current was severely reduced in steps from -40 $\mathrm{mV}$ (Fig. 7B2). The characteristics of this current (voltage-dependent activation, inactivation at sustained depolarized volt- 

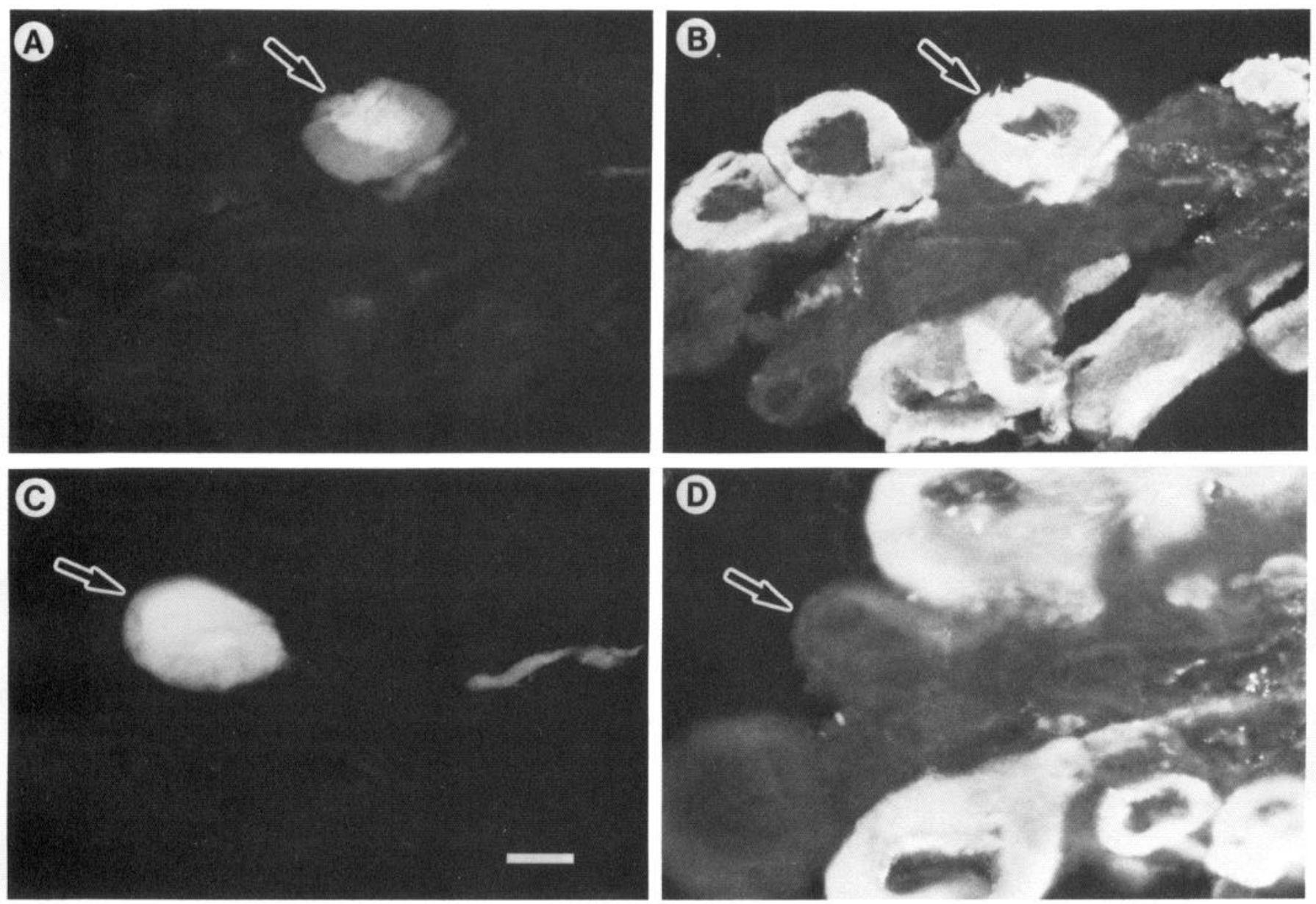

Figure 6. $\mathrm{B} 15$, but not $\mathrm{B} 16$, contains $\mathrm{SCP}_{\mathrm{b}}$ immunoreactivity. $A$, Lucifer yellow-filled $\mathrm{B} 15$ is indicated by the arrow. Note that the nucleus has accumulated dye and displays intense fluorescence. $B$, Anti-SCP $\mathrm{b}_{\mathrm{b}}$ histochemical staining of the same section as in $A$ using a filter to visualize the rhodamine-coupled secondary antibody. Arrow points to immunoreactive B15, while some neighboring cells are not immunoreactive. Note that the nucleus does not stain. $C$, Lucifer yellow-filled B16 is indicated by the arrow. $D$, Anti-SCP $\mathrm{b}_{\mathrm{b}}$ histochemical staining of the same section as in $C$ visualizing the rhodamine-coupled secondary antibody. $\mathrm{B} 16$ does not contain $\mathrm{SCP}_{\mathrm{b}}$ immunoreactivity; however, some neighboring cells are immunoreactive. Calibration bar $(A-D), 25 \mu \mathrm{m}$.

ages) are very similar to the $I_{\mathrm{a}}$ current described previously in other neurons (Connor and Stevens, 1971; Thompson, 1977).

The presence of a transient outward current in B15 implies that the neuron will resist firing during a short synaptic depolarization because the current is activated by excitation from the normal resting membrane level of near $-70 \mathrm{mV}$. Alternatively, when $\mathrm{B} 15$ is depolarized over a long period by the actions of a transmitter (e.g., 5-HT or $\mathrm{SCP}_{\mathrm{b}}$ ), or by large and prolonged synaptic excitation, the transient outward current will be inactivated and B15 will respond quickly to additional excitatory synaptic input. These properties of B15 strongly resemble those of the ink gland motoneurons of Aplysia, which also exhibit very negative resting membrane potentials and large transient outward currents (Byrne et al., 1979). B16 also has a transient outward current, but due to B16's more depolarized resting membrane potential the current is largely inactivated at rest (data not shown).

\section{Discussion}

Candidate transmitters act at different hierarchical levels

We have described the responses of the identified motoneurons $\mathrm{B} 15$ and $\mathrm{B} 16$ and the premotor interneurons $\mathrm{B} 4 / \mathrm{B} 5$ to a number of candidate neurotransmitters. A summary of our results is shown in Figure 8 and Table 1. Interestingly, each peptide had a set of distinct effects, not only on the patterns of activity elicited by a CPG(s), but also in their direct actions on the neurons studied. It was previously shown that 2 of the substances ( $\mathrm{SCP}_{\mathrm{b}}$ and 5-HT) act on the ARC muscle (Weiss et al., 1978; Lloyd et al., 1984), and there is preliminary evidence that ELH and FMRFamide immunoreactivity can also be found on the ARC muscle (T. Kreiner and R. Scheller, personal communication). Therefore, these candidate neurotransmitters or neuromodulators act at each level within the known portions of the feeding motor system (CPG, interneurons, motoneurons, and muscle; see Fig. 8). For instance, $\mathrm{SCP}_{\mathrm{b}}$ induces the CPG from a quiescent state, depolarizes the motor neuron $\mathrm{B} 15$ directly, and then potentiates the effects of the motoneurons on the ARC muscle, thus acting in a coordinated fashion on different hierarchical levels within the feeding motor system.

\section{Motoneurons B15 and B16 have different intrinsic properties}

B15 and B16 share many characteristic features. They are both cholinergic motoneurons innervating the ARC muscle and are both excited by $5-\mathrm{HT}$ and inhibited by FMRFamide. The neu- 

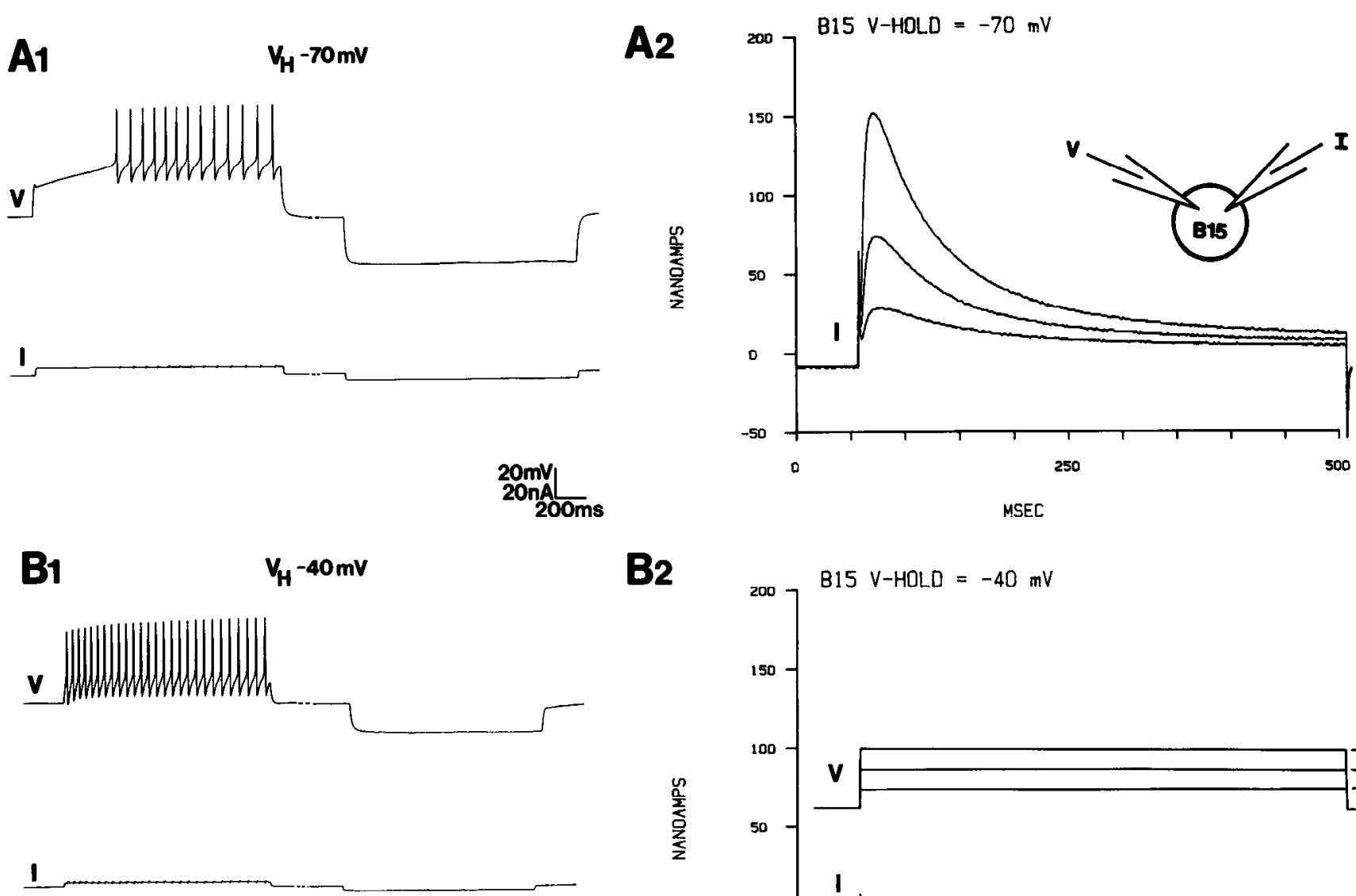

B2

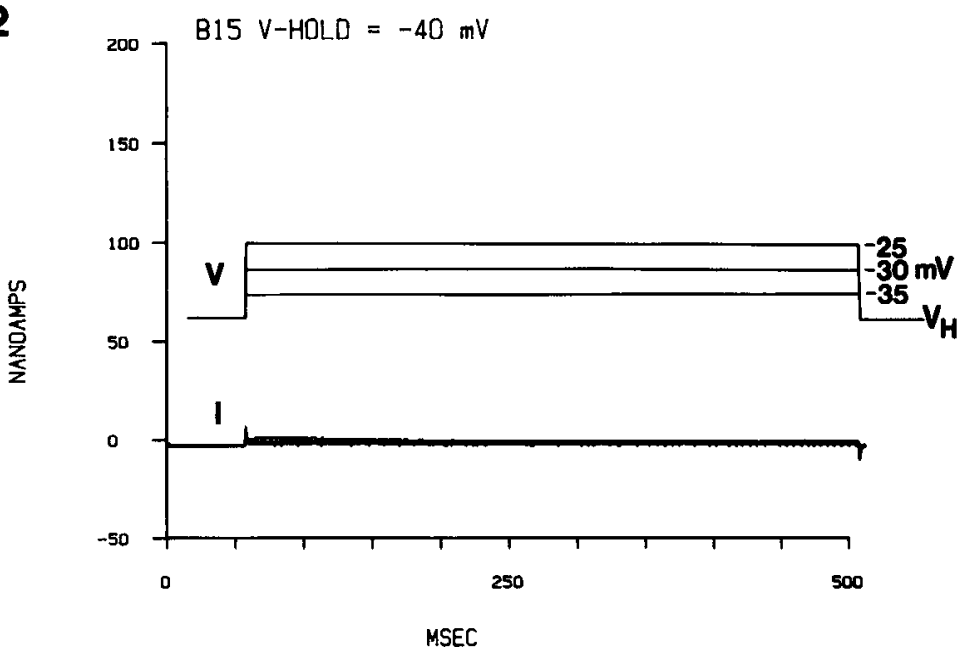

Figure 7. Current and voltage clamp of B15. A1, In current clamp, a step depolarization produced a delayed firing in B15. The delay was not due to the membrane time constant. Two electrodes, for voltage recording and current passing, were inserted into B15 (see inset $A 2$ ). From an initial holding potential of $-70 \mathrm{mV}$, a depolarizing (first pair of traces) and a hyperpolarizing (second pair of traces) current pulse of equal magnitudes were given to B15 A2, Large transient outward current elicited by depolarizing voltage steps during voltage-clamp recording. In voltage clamp (see Materials and Methods), B15 was given steps to $-35,-30$, and $-25 \mathrm{mV}$ from a holding potential of $-70 \mathrm{mV}$. Data were recorded digitally and then plotted on an HP plotter (7470A). Inset is a schematic showing that voltage $(V)$ and current $(I)$ electrodes were inserted into B15 for both the current clamp and voltage-clamp experiments. $B 1$, In current clamp, a step depolarization from a holding potential of $-40 \mathrm{mV}$ gave rise to repetitive firing without delay. Recording situation the same as in $A l$ but from an initial holding voltage of $-40 \mathrm{mV}$. B2, Transient outward current inactivated at a holding potential of $-40 \mathrm{mV}$. Recording conditions were the same as in A2 but with a holding voltage of $-40 \mathrm{mV}$. Inset exhibits the voltage steps used for $\mathrm{A} 2$ and $\mathrm{B} 2$.

rons receive common synaptic inputs (e.g., both are inhibited by $\mathrm{B} 4$ and the tonic inhibitors, and are excited coordinately in $\mathrm{SCP}_{\mathrm{b}}$ - and ELH-induced bursts). Each neuron also possesses unique properties. The most obvious difference between them is the much greater facilitation at the neuromuscular junction displayed by B15 (Cohen et al., 1978), which results in a greater tension response (unpublished observations). In this paper we have outlined a number of additional differences. The neurons respond differently to the peptides, $\mathrm{B} 15$ being excited by $\mathrm{SCP}_{\mathrm{b}}$, but not ELH, and B16 being excited by ELH, but not $\mathrm{SCP}_{b}$. The synaptic inputs to the cells can differ, as evident from the opposite signs of synaptic input received during the bursts induced by 5-HT and during spontaneous activity (Cohen et al., 1978; and unpublished observations). B15 resists depolarization due to its low resting membrane potential and $I_{\mathrm{a}}$-like current, while B16 is easily excited and can exhibit endogenous bursting activity (Kirk and Scheller, 1986). Finally, B15 contains $\mathrm{SCP}_{\mathrm{b}}$
Table 1. Effects of transmitters on different levels of the feeding hierarchy

\begin{tabular}{lllllll} 
& \multicolumn{7}{l}{ Site of action } \\
\cline { 2 - 6 } Transmitter & Muscle & B15 & B16 & B4 & CPG & $\begin{array}{l}\text { Tonic } \\
\text { IPSPs }\end{array}$ \\
\hline ELH & $?$ & 0 & ++ & 0 & + & 0 \\
FMRFamide & $?$ & - & - & + & $-1+$ & - \\
SCP $_{\text {b }}$ & ++ & ++ & 0 & 0 & ++ & ++ \\
5-HT & ++ & ++ & ++ & ++ & ++ & ++
\end{tabular}

The symbols have the following meanings: 0 , no effect; + , weak stimulatory effect; ++ , strong stimulatory effect; - , inhibitory effect; ?, not determined. The $-/+$ for FMRFamide effects on the CPG reflects the fact that, although it usually inhibited ongoing synaptic inputs to the cells, FMRFamide also occasionally induced synaptic inputs. Effects of enhanced tension on the muscle have been published previously (Weiss et al., 1978; Lloyd et al., 1984). Effects on the CPG were measured by the ability to produce coordinated synaptic input to B4, B15, and B16. 


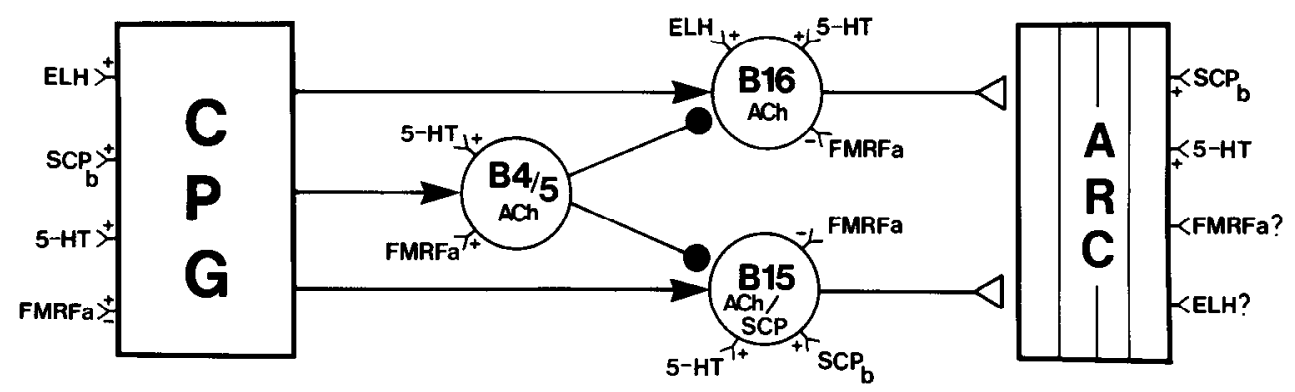

Figure 8. Summary of our present knowledge of the effects of candidate neurotransmitters on components of the Aplysia feeding system. The symbols used have the following meanings: $Y$, receptor for the indicated substance, with the direction of the action indicated by plus (excitation) or minus (inhibition) signs; unfilled triangles, direct excitatory connection; filled circles, direct inhibitory connection; arrows between components indicate complex functional connections. The known transmitters for each cell are indicated inside the cell. Abbreviations: ARC, accessory radular closer muscle; CPG, central pattern generator; ACh, acetylcholine; ELH, egg-laying hormone; $\mathrm{SCP}_{\mathrm{b}}$, small cardioactive peptide; FMRFamide, PheMetArgPhe-NH $\mathrm{NH}_{2}$ 5-HT, serotonin.

immunoreactivity while B16 does not. These findings suggest that the 2 neurons have unique roles in generating activities of the buccal mass.

\section{5-HT may mimic responses to the metacerebral cell}

Since the bursting patterns observed in this study were still seen when the buccal commissure was severed, it is clear that at least 1 oscillator for the CPG resides in each hemiganglion. However, some of the neurons responsible for initiating and modulating the CPG may not be located in the buccal ganglia, since lesions of the cerebral-buccal connective abolish the consummatory phase of feeding (Kupfermann, 1974b). The metacerebral cell (MCC), which exhibits firing correlated with food-induced arousal of the feeding system (Weiss et al., 1978), is located in the cerebral ganglion and innervates the buccal ganglia and musculature (Schwartz and Shkolnik, 1981). Furthermore, the MCC is a scrotonergic neuron that, when fired, enhances bursting output in the buccal ganglia, directly excites motoneurons B15 and $B 16$, and enhances the tension response of the ARC muscle to input from the motoneurons (Weiss et al., 1978). One explanation for many of the responses observed after application of 5-HT is that addition of the transmitter is mimicking the firing of the MCC. The 5-HT response is not mimicking effects of dopamine, as the response could not be elicited with equal concentrations of dopamine $(n=2)$; therefore, 5-HT is not acting at dopaminergic receptors (see Trimble and Barker, 1984). The other candidate transmitters may also be acting by simulating input from modulatory cells that use the substances as intercellular messengers.

\section{B15 contains $S C P_{b}$ immunoreactivity}

The observation that $\mathbf{B} 15$ contains $\mathbf{S C P}_{\mathrm{b}}$ immunoreactivity is consistent with previous findings. $\mathrm{SCP}_{\mathrm{b}}$ immunoreactivity has been observed at the ARC muscle (Lloyd et al., 1984), and $\mathrm{SCP}_{\mathrm{b}}$ acts at the muscle to enhance tension in response to motoneuron stimulation (Lloyd et al., 1984). Thus, firing B15 may release $\mathrm{SCP}_{\mathrm{b}}$ at the ARC muscle and enhance the tension produced by its own activity. Also, as B15 is depolarized by $\operatorname{SCP}_{b}$ (see above), the peptide may be acting in an autoregulatory fashion.

Peptidergic motoneurons have been documented previously in other systems (Adams and O'Shea, 1983; Bishop et al., 1984). It is becoming clear that motoneurons not only control the action of muscles with classical transmitters (e.g., ACh), but may also exert modular control over muscles by use of a second peptidergic transmitter.

\section{Possible roles for the candidate transmitters}

One method of coordinating a number of different but similar motor outputs is to impose modulatory controls onto a set of fixed synaptic connections. This theory is supported by evidence from a number of studies on invertebrate motor control. In Pleurobranchea, a number of modulatory neurons have been identified that are associated with the different rhythmic patterns of injestion and ejestion (Croll et al., 1985). Getting and Dekin (1985) propose that a single network of interneurons can generate 2 distinct motor outputs in the Tritonia swimming circuit. Finally, the outputs of an identified CPG in the stomatogastric nervous system of the lobster are modified by the actions of a number of neurotransmitters (Marder, 1984). Our data are also consistent with this proposal. Each candidate transmitter has unique modulatory actions not only on the CPG(s), as measured by the induction of rhythmic output, but also on the other constituents of the motor system (motoneurons and muscle). ELH, one of the transmitters we studied, has already been associated with a number of unique motor movements involved in egg-laying behavior (Arch and Smock, 1977; Cobbs and Pinsker, $1982 \mathrm{a}, \mathrm{b})$. Thus, it is becoming increasingly clear that the use of multiple modulators greatly expands the number of behaviors that can be generated from a single neuronal circuit.

\section{References}

Adams, M. E., and M. O'Shea (1983) Peptide cotransmitter at a neuromuscular junction. Science 221: 286-288.

Arch, S., and T. Smock (1977) Egg-laying behavior in Aplysia californica. Behav. Biol. 19: 45-54.

Benjamin, P. R., and R. M. Rose (1980) Interneuronal circuitry underlying cyclical feeding in gastropod molluscs. Trends Neurosci. 3: 272-274.

Bishop, C. A., J. J. Wine, and M. O'Shea (1984) Neuropeptide proctolin in postural motoneurons of crayfish. J. Neurosci. 4: 2001-2009.

Byrne, J. H., E. Shapiro, N. Dieringer, and J. Koester (1979) Biophysical mechanisms contributing to inking behavior in Aplysia. J. Neurophysiol. 5: 1233-1250.

Chiu, A. Y., M. W. Hunkapiller, E. Heller, D. K. Stuart, L. E. Hood, and F. Strumwasser (1979) Purification and primary structure of the neuropeptide egg-laying hormone of Aplysia californica. Proc. Natl. Acad. Sci. USA 76: 6656-6601.

Cobbs, J. S., and H. M. Pinsker (1982a) Role of bag cells in egg deposition of Aplysia brasiliana. I. Comparison of normal and elicited behavior. J. Comp. Physiol. 147: 523-535.

Cobbs, J. S., and H. M. Pinsker (1982b) Role of bag cells in egg deposition of Aplysia brasiliana. II. Contribution of egg movement to elicited behaviors. J. Comp. Physiol. 147: 537-546.

Cohen, S. L., K. R. Weiss, and I. Kupfermann (1978) Motor control of buccal muscles in Aplysia. J. Neurophysiol. 41: 157-179. 
Connor, J. A., and C. F. Stevens (1971) Voltage clamp studies of a transient outward current in gastropod neural stomata. J. Physiol. (Lond.) 213: 21-30.

Croll, R. P., M. P. Kovac, W. J. Davis, and E. M. Matera (1985) Neural mechanisms of motor program switching in the mollusc Pleurobran chaea. III. Role of the paracerebral neurons and other identified brain neurons. J. Neurosci 5: 64-71.

Delcomyn, F. (1980) Neural basis of rhythmic behavior in animals. Science 210: 492-498.

Gardner, D. (1971) Bilateral symmetry and interneuronal organization in the buccal ganglia of Aplysia. Science 173:550-553.

Gardner, D. (1977) Interconnection of identified multiaction interneurons in buccal ganglion of Aplysia. J. Neurophysiol. 40: 349-361.

Getting, P. A. (1981) Mechanism of pattern generation underlying swimming in Tritonia. I. Neuronal network formed by monosynaptic connections. J. Neurophysiol. 46: 65-79.

Getting, P. A., and M. S. Dekin (1985) Tritonia swimming. In Model Neural Networks and Behavior, A. S. Selverston, ed., pp. 1-20, Plenum, New York.

Goldstein, R., H. B. Kistler, Jr., H. W. M. Steinbusch, and J. H. Schwartz (1984) Distribution of serotonin-immunoreactivity in juvenile Aplysia. Neuroscience 11: 535-547.

Grillner, S. (1985) Neurobiological basis of rhythmic motor acts in vertebrates. Science 228: 143-149.

Jahan-Parwar, B., A. H. Wilson, Jr., and S. Fredman (1983) Role of proprioceptive reflexes in the control of feeding muscles of Aplysia. J. Neurophysiol 49: 1469-1480.

Kandel, E. R. (1979) Behavioral Biology of Aplysia, Freeman, New York

Kater, S. B. (1974) Feeding in Helisoma trivolvis: The morphological and physiological basis of a fixed action pattern. Am. Zool. 14: 10171036

Kirk, M. D., and R. H. Scheller (1986) Egg-laying hormone of Aplysia induces a voltage-dependent slow inward current carried by $\mathrm{Na}^{+}$in an identified motoneuron. Proc. Natl. Acad. Sci. USA 83: 301 7-3021.

Kirk, M. D., S. H. Thompson, and R. H. Scheller (1985) A voltage clamp analysis of egg-laying hormone and serotonin effects on the identified motoneuron B16 of Aplysia. Soc. Neurosci. Abstr. 11: 641 .

Krieger, D. I. (1983) Brain peptides: What, where, and why? Science 222: 975 .

Kupfermann, I. (1974a) Feeding behavior in Aplysia: A simple system for the study of motivation. Behav. Biol. 10: 1-26.

Kupfermann, I. (1974b) Dissociation of the appetitive and consummatory phases of feeding behavior in Aplysia: A lesion study. Behav. Biol. 10: 89-97.

Lloyd, P. E., and A. O. D. Willows (1980) Identified peptidergic neurons activate the feeding motor program of Tritonia. Soc. Neurosci. Abstr. 6: 704

Lloyd, P. E., I. Kupfermann, and K. R. Weiss (1984) Evidence for parallel actions of a molluscan neuropeptide and serotonin in mediating arousal in Aplysia. Proc. Natl. Acad. Sci. USA 81: 2934-2937.

Lloyd, P. E., A. C. Mahon, I. Kupfermann, J. L. Cohen, R. H. Scheller, and K. R. Weiss (1985) Biochemical and immunocytological localization of molluscan small cardioactive peptides in the nervous system of Aplysia californica. J. Neurosci. 5: 1851-1861.

Mahon, A. C., P. E. Lloyd, K. R. Weiss, I. Kupfermann, and R. H. Scheller (1985) The small cardioactive peptides A and B of Aplysia are derived from a common precursor molecule. Proc. Natl. Acad. Sci. USA 82: 3925-3929.

Marder, E. (1984) Mechanisms underlying neurotransmitter modulation of a neuronal circuit. Trends Neurosci. $7: 48-53$.
McAllister, L. B., R. H. Scheller, E. R. Kandel, and R. Axel (1983) In situ hybridization to study the origin and fate of identified neurons. Science 222: 800.

Murphy, A. D., K. Lukowiak, and W. K. Stell (1985) Peptidergic modulation of patterned motor activity in identified neurons in Helisoma. Proc. Natl. Acad. Sci. USA 82: 7140-7144.

Ram, J. L. (1982) Aplysia egg-laying hormone increases excitatory input into a rectractor muscle of the buccal mass. Brain Res. 236: 505-510.

Ram, J. L. (1983) Neuropeptide activation of an identifiable buccal ganglia motoneuron in Aplysia. Brain Res. 288: 177-186.

Ram, J. L., K. A. Heller, and Z. Levran (1986) Sensitivity of a peptide activated neuron in Aplysia to serotonin and cyclic AMP relevant agents. Comp. Biochem. Physiol. 83C: 279-283.

Rosen, S. C., K. R. Weiss, J. L. Cohen, and I. Kupfermann (1982) Interganglionic cerebral-buccal mechanoafferents of Aplysia: Receptive fields and synaptic connections to different classes of neurons involved in feeding behavior. J. Neurophysiol. 48: 271-288.

Rosen, S. C., I. Kupfermann, R. S. Goldstein, and K. R. Weiss (1983) Lesion of a serotonergic modulatory neuron in Aplysia produces a specific defect in feeding behavior. Brain Res. 260: 151-155.

Russell, D. R., and D. K. Hartline (1982) Slow active potentials and bursting motor patterns in pyloric network of the lobster, Panulirus interruptus. J. Neurophysiol. 48: 914-937.

Schaefer, M., M. R. Picciotto, T. Kreiner, R. R. Kaldany, R. Taussig, and R. H. Scheller (1985) Aplysia neurons express a gene encoding multiple FMRFamide neuropeptides. Cell 41: 457-467.

Scheller, R. H., R. R. Kaldany, T. Kreiner, A. C. Mahon, J. R. Nambu, M. Schaefer, and R. Taussig (1984) Neuropeptides: Modulators of behavior in Aplysia. Science 225: 1300-1308.

Schwartz, J. H., and L. J. Shkolnik (1981) The giant serotonergic neuron of Aplysia: A multitargeted nerve cell. J. Neurosci. 1: 606619.

Selverston, A. I. (1980) Are central pattern generators understandable? Behav. Brain Sci. 3: 535-571.

Selverston, A. I., D. F. Russell, J. P. Miller, and D. G. King (1976) The stomatogastric nervous system: Structure and function of a small neural network. Prog. Neurobiol. 7: 215-290.

Shyamala, M., J. R. Nambu, and R. H. Scheller (1986) Expression of the egg-laying hormone gene family in the head ganglion of Aplysia. Brain Res. 371: 49-57.

Snyder, S. H., and R. B. Innis (1979) Peptide neurotransmitters. Annu. Rev. Biochem. 48: 755-782.

Stent, G. S., W. B. Kristan, Jr., W. O. Friesan, C. A. Ort, M. Poon, and R. L. Calabrese (1978) Neuronal generation of the leech swimming movement. Science 200: 1348-1356.

Stuart, D. K., and F. Strumwasser (1980) Neuronal sites of action of a neurosecretory peptide, egg-laying hormone, in Aplysia californica. J. Neurophysiol. 43: 499-519.

Thompson, S. H. (1977) Three pharmacologically distinct potassium channels in molluscan neurons. J. Physiol. (Lond.) 265: 465-488.

Trimble, D. T., and D. L. Barker (1984) Activation by dopamine of patterned motor output from the buccal ganglia of Helisoma trivolvis. J. Neurobiol. 15: 37-48.

Weiss, K. R., J. L. Cohen, and I. Kupfermann (1978) Modulatory control of buccal musculature by a serotonergic neuron (metacerebral cell) in Aplysia. J. Neurophysiol. 41: 181-203.

Weiss, K. R., H. J. Chiel, U. Koch, and I. Kupfermann (1986) Activity of an identified histaminergic neuron in arousal of feeding behavior in semi-intact Aplysia. J. Neurosci. 6: 2403-2415. 